\title{
Research Paper: Internet Dependence and Sensation Seeking in Youth With Moderate Cerebral Palsy
}

\author{
Saeed Rezayi ${ }^{1}$, Omid Massah ${ }^{2 *}$
}

1. Allame Tabataba'i University, Tehran, Iran

2. Substance Abuse and Dependence Research Center, University of Social Welfare and Rehabilitation Sciences, Tehran, Iran.

\begin{tabular}{|c|c|}
\hline 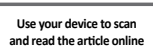 & \\
\hline 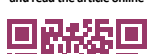 & Citation: Rezayi S, Massah O. Internet Dependence and Sensation Seeking in Youth With Moderate Cerebral Palsy. Iranian \\
\hline 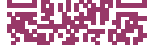 & Rehabilitation Journal. 2017; 15(2):95-102. https://doi.org/10.18869/NRIP.IRJ.15.2.95 \\
\hline 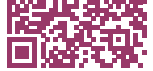 & doil: https://doi.org/10.18869/NRIP.IRJ.15.2.95 \\
\hline
\end{tabular}

Article info:

Received: 14 Nov. 2016

Accepted: 10 Mar. 2017

\section{Keywords:}

Sensation seeking, Internet dependence, Cerebral palsy, Youth

\section{ABSTRACT}

Objectives: The present study examined excessive internet use of youths with moderate Cerebral Palsy (CP) and their psychological states in Sensation Seeking (SS).

Methods: This study followed descriptive and correlation research design. Individuals aged 15 to 25 years with $\mathrm{CP}$ who were referred to Tehran rehabilitation centers were considered in the study. The study sample $(\mathrm{n}=150)$ was randomly divided into two groups of internet dependents $(n=75$; boys $=45$ and girls $=30)$ and non-dependents $(n=75$; boys $=45$ and girls $=30)$. Internet Addiction Test and Sensation Seeking Scale have been used for data gathering. Data were analyzed by using Pearson correlation coefficients, multivariable regression, $\mathrm{x}^{2}$ and $\mathrm{T}$ tests.

Results: Compared to non-dependents, the internet dependent group reported significantly more negative internet influences on daily routines such as clinical problems, poor school performance, regular nutrition, and relation with friends and family members. Both the groups pointed that internet use enhanced virtual peer relationships and provided up-to-date information. Internet dependents (both gender) scored significantly higher on disinhibition sensation seeking subscale than the internet non-dependents. However, these two groups (both gender) did not demonstrate significant differences in life experience seeking and thrill and adventure seeking subscales, but their differences were sizable.

Discussion: It seems that internet applications direct or indirectly motive users to be online for more hours than necessary. This is true for CP patients given their motor impairment. Based on this research result, it seems that persons with $\mathrm{CP}$ because of lack of physical activities, motive by internal stimulus and seeking their sensation from external stimulus like internet application as well as for person with $\mathrm{CP}$ surfing in internet world and spent too much time on the internet is leisure time not activity time.

\section{* Corresponding Author:}

Address: Substance Abuse and Dependence Research Center, University of Social Welfare and Rehabilitation Sciences, Tehran, Iran. 


\section{Introduction}

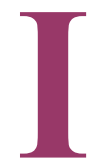

nternet Addictive Behavior (IAB) is defined as a behavioral pattern characterized by a loss of control over internet use [1]. This behavior results in segregation of social, educational, and leisure activities or health care inconsideration $[2,3]$. The internet has become the main source of information, entertainment, and most importantly, connection among youths; this indeed could take too much time of adults who communicate through media $[4,5]$.

Internet is used by a large number $(68 \%)$ of Iranian teenagers aged 12 to 19 years. Despite all the advantages, a disproportionate amount of time passed on the internet triggers many problems [1]. Kimberly Young defined internet addiction for the first time in 1996 and provoked conflicts among researchers and clinicians. In fact, no exact definition of 'internet addiction' has been proved yet, but academics believe in the existence of such term anyhow.

Young (1999) suggested the following criteria to be considered when diagnosing IAB existence of a significant clinical impairment or distress following obsession with the internet, craving to be online for a long period of time to gain satisfaction, failed frequent attempts to control internet use, restlessness, mood related issues or irritation once making efforts to stop/end the use of internet, being online more than the planned time, putting a relationship or social status at risk due to internet use, disguise exceeded use of internet with therapy, and stay online as a coping strategy for depression or other problems [6].

Extreme use of internet may affect an individual's health negatively. It may cause sleep-related disorders, weakened immune system, constant fatigue, back or eye problems, impaired hygiene, communication problems, educational conflicts, and issues related to internet use such as sexual abuse, etc. [7, 8]. Numerous aspects of this disorder have been studied over time. Since DSMIV does not provide the criteria for internet addiction, it is difficult to specify its precise diagnosis [9]. Academics claim that the overuse of internet may cause pathological problems and addiction, and it is often referred to as addiction to technology [10]. Of the entire diagnoses referred to in DSM-IV, pathological gambling is the most similar to the pathological nature of internet usage.

Young (1998) suggested that internet addiction does not happen intrinsically, but the pathological use of the internet is triggered by particular applications, programs and features [6]. On the other hand, Griffiths reported that pathological use of the internet could be a result of specific activities and their structural features (characteristics applied in design of supplier's products) evolved with reinforcement $[10,11]$.

For instance, too much 'interactions' in chat rooms and games could lead to surrogate actualities to the users. There is a strong relationship between excessive use of internet and social segregation, low self-esteem [12], impulsive and aggressive behaviors [4], and male gender and compulsive personality traits [12]. Some personality traits including being introvert or extrovert explore contradictory behaviors online [13]. Sensation Seeking (SS) is an attribute characterized by the purpose of finding diverse, novel, complicated and severe affections and experiments, and desire to risk social, legal or financial sources in this regard [14].

Zuckerman (1969) has proposed a theory of sensory deprivation based on the construct called the optimal level of stimulation. Like other personality traits, individuals differ largely on SS. Research shows that SS needs heritage and biological readiness [15], although some researchers emphasize on its cognitive and learning aspects [13]. In professional groups like sports teams or artists, SS may emerge in assertive or risky behavior forms [16]; however, these risky behaviors may set the stage for the development of delinquency [17]. In delinquent groups, SS may show up in some other forms of behaviors such as drug abuse, drinking problem [18, 19], and antisocial behaviors [20].

$\mathrm{SS}$ is a significant feature during the adolescence period [21] and highly related to some risk or adventure and disruptive behaviors, such as fighting, risky relation, drug use, drinking and driving, diving, or parachuting [22-24]. Surfing internet is considered as an adventure around the world of high tech and, therefore, could be related to SS Cerebral Palsy (CP) is defined as multiple brain damage over its early development, and usually during fetus life or sometimes on birth. Premature birth, infections, impairment in metabolism or hormones, genetic issues and brain bleeding are the etiological reasons to $\mathrm{CP}$.

The CP patients cannot experience physical activities compared to typical peers because of motor limitation. However, they desire to be among peer groups and in public settings, share and double interactions with others and social activities, etc. [25]. Since the internet world does not have any limitation even for CP patients, they can have many experiences as other typical people. Therefore, it can be predictable that $\mathrm{CP}$ patients will be permanent users of 
the internet. Therefore, the main aim of this study was to investigate the relationship between internet dependence or addiction and SS among CP patients. The following hypothesis was examined: there is a significant relation between SS capacity in CP patients and internet dependence.

\section{Methods}

\section{Participants}

The current study follows a descriptive and correlation research design. This study included 150 individuals aged 15 to 25 years who were diagnosed with CP (girls and boys) and received rehabilitation services in Tehran schools and rehabilitation centers. They were randomly recruited from a large $\mathrm{CP}$ community as sample for the current study. The sample was then divided into two groups: internet dependents $(n=75 ; 45$ boys and 30 girls) and non-dependents ( $\mathrm{n}=75 ; 45$ boys and 30 girls).

\section{Measures}

Internet Addiction Test (IAT) (26) was used for identifying internet dependency ratio. It included 20 questions with five-point Likert response format (rarely, sometimes, often, very often and always). A score between 20-39 indicated the individual to have medium internet addiction, 40-69 indicated high addiction, and 70-100 indicated severe addiction to the internet. The internal consistency of the IAT subscales was acquired by calculating the Cronbach's alpha, which was found to be 0.84 to 0.86 . The sum reliability score was reported to be 0.94. The Sensation Seeking Scale (SSS)-4 was applied for assessing the straits of SS [14]. This scale displayed sizable reliability indexes, and its Cronbach's alpha from 0.61 to 0.81 . The gathered data were analyzed by using Pearson correlation coefficients, regression analysis, chi-square test $\left(\mathrm{X}^{2}\right)$, and t tests.

\section{Results}

As seen in Table 1, there is a significant relationship between the background of users (gender and records) and internet addiction. The internet addiction ratio of girls is significantly lower than that of boys. It was also found that the history of use of internet applications is more influentioal in internet addiction. Table 2 demonstrated that the scores of internet-dependent CP patients are significantly more than that of non-dependents for all internet applications, especially social networking sites like Facebook. Table 3 demonstrated the scores of $\mathrm{CP}$ patients with internet dependence and non-dependents in IAT subscales. The psychological characteristics (compulsive use/withdrawal and tolerance) of internet dependent individuals were more affected by the overuse of internet than the non-dependents. They were also severely affected in other measures such as family, school, health, interpersonal relationships, and finance.

Table 4 demonstrated the scores of CP patients with internet dependence and non-dependence with respect to internet influence on life aspects' subscales. It was found that the life aspects of internet-dependent individuals were more affected by the over-use of the internet than that of the non-dependents. Table 5 demonstrates the scores of CP patients with internet dependence and nondependents in SS subscales. Interestingly, we found only one SS dimension (disinhibition) to have a significant influence. Table 6 demonstrates that there is a significant relationship between internet dependence subscales and disinhibition in SS scales. Table 7 shows that there is a significant relation between internet dependence subscales and two dimensions of SS scales (susceptibility to boredom and disinhibition).

\section{Discussion}

Our results showed that problematic internet usage of internet-dependent CP patients affected them in many aspects like psychological state (compulsive use/withdrawal and tolerance), social behaviors, emotional capability, daily life harmony, making and developing relation, sleep and rest situation, academic states, and many other dimensions of life (Tables 3, 4). These findings are in line with previous findings [27]. Our study revealed that there is a significant relation between backgrounds

Table 1. Frequencies and $X^{2}$ test of internet dependents and non-dependents differences on gender and Internet experience

\begin{tabular}{|c|c|c|c|c|c|c|}
\hline & & Internet-Dependents & Non-Dependents & Sum & $X^{2}$ & df \\
\hline \multirow{3}{*}{ Gender } & CP. Boys & 45 & 45 & 90 & & \\
\hline & & & & & $13.154^{* *}$ & 1 \\
\hline & CP. Girls & 30 & 30 & 60 & & \\
\hline Internet Experience & $<1$ Year & 18 & 21 & 39 & $19.655^{* *}$ & 4 \\
\hline
\end{tabular}


Table 2. Average amounts of time spent (hours/ per week), standard deviation, and t tests on various internet applications for $\mathrm{CP}$ patients with Internet dependents $(\mathrm{N}=75)$ and non-dependents $(\mathrm{N}=75)$

\begin{tabular}{|c|c|c|c|c|}
\hline Internet Usage (Hours/Per Week) & $\mathbf{C P}$ & Mean & SD & T-test \\
\hline \multirow{3}{*}{ WWW } & Dependent & 4.76 & 5.89 & \multirow{3}{*}{$3.88^{* *}$} \\
\hline & & & & \\
\hline & Non-dependent & 3.11 & 4.01 & \\
\hline \multirow{3}{*}{ Chat room/ IRC } & Dependent & 6.54 & 7.19 & \multirow{3}{*}{$3.89^{* *}$} \\
\hline & & & & \\
\hline & Non-dependent & 2.66 & 3.23 & \\
\hline \multirow{3}{*}{ Social networking (Facebook) } & Dependent & 9.13 & 8.44 & \multirow{3}{*}{$5.27^{* *}$} \\
\hline & & & & \\
\hline & Non-dependent & 6.05 & 6.99 & \\
\hline \multirow{3}{*}{ Twitter } & Dependent & 7.41 & 8.78 & \multirow{3}{*}{$4.54^{* *}$} \\
\hline & & & & \\
\hline & Non-dependent & 3.33 & 4.59 & \\
\hline \multirow{3}{*}{ E-mail } & Dependent & 5.91 & 7.22 & \multirow{3}{*}{$2.908^{* *}$} \\
\hline & & & & \\
\hline & Non-dependent & 4.84 & 5.61 & \\
\hline \multirow{3}{*}{ Forums } & Dependent & 2.01 & 3.39 & \multirow{3}{*}{$3.786^{*}$} \\
\hline & & & & \\
\hline & Non-dependent & 0.510 & 1.10 & \\
\hline \multirow{3}{*}{ Viber } & Dependent & 3.89 & 4.83 & \multirow{3}{*}{$3.88^{* *}$} \\
\hline & & & & \\
\hline & Non-dependent & 1.71 & 2.63 & \\
\hline \multirow{3}{*}{ Net game/ MUD } & Dependent & 2.09 & 3.90 & \multirow{3}{*}{1.006} \\
\hline & & & & \\
\hline & Non-dependent & 1.05 & 2.20 & \\
\hline \multirow{3}{*}{ Youtube } & Dependent & 1.89 & 2.83 & \multirow{3}{*}{1.886} \\
\hline & & & & \\
\hline & Non-dependent & 0.771 & 1.63 & \\
\hline \multirow{3}{*}{ Downloading } & Dependent & 0.645 & 1.77 & \multirow{3}{*}{0.845} \\
\hline & & & & \\
\hline & Non-dependent & 0.032 & 0.990 & \\
\hline \multirow{3}{*}{ Weblogs } & Dependent & 5.41 & 4.99 & \multirow{3}{*}{0.925} \\
\hline & & & & \\
\hline & Non-dependent & 5.02 & 4.86 & \\
\hline \multirow{3}{*}{ Newsgroup or surfing } & Dependent & 3.09 & 3.77 & \multirow{3}{*}{0.808} \\
\hline & & & & \\
\hline & Non-dependent & 2.97 & 3.00 & \\
\hline
\end{tabular}

${ }^{* *} \mathrm{P}<0.001$

of user, gender, records and internet addiction. As mentioned before, the number of girls addicted to the internet is significantly lower than that of boys. Moreover, the history and experience of internet application is more influentional in internet addiction [28, 29].

Our results showed that the scores of CP patients with internet dependence are significantly more than that of non-internet dependents for all internet applications (Table 2). Interestingly, the results of the SS traits and internet dependency were against our research hypothesis. Our hypothesis stated that there is a significant relationship between internet dependency and SS trait in users with CP. Contrarily, as seen in Table 5, only one dimension of SS subscale (disinhibition) had a significant relationship with internet dependency. Similarly, Lavin 
Table 3. Means, standard deviation, and t tests on IAT subscales and overall score for internet dependents ( $N=75)$ and nondependents $(\mathrm{N}=75)$

\begin{tabular}{|c|c|c|c|c|}
\hline Internet Dependence & CP & Mean & SD & T-test \\
\hline \multirow{3}{*}{ Compulsive use/ Withdrawal } & Dependent & 11.23 & 2.61 & \multirow{3}{*}{$9.62^{* *}$} \\
\hline & & & & \\
\hline & Non-dependent & 8.81 & 3.02 & \\
\hline \multirow{3}{*}{ Tolerance } & Dependent & 14.43 & 3.68 & \multirow{3}{*}{$10.52^{* *}$} \\
\hline & & & & \\
\hline & Non-dependent & 9.16 & 2.83 & \\
\hline \multirow{3}{*}{ Related problems: Family, school, health } & Dependent & 9.93 & 2.60 & \multirow{3}{*}{6.19} \\
\hline & & & & \\
\hline & Non-dependent & 5.94 & 5.66 & \\
\hline \multirow{3}{*}{ Related problems: Interpersonal and Finance } & Dependent & 4.64 & 5.91 & \multirow{3}{*}{5.83} \\
\hline & & & & \\
\hline & Non-dependent & 3.49 & 6.19 & \\
\hline \multirow{3}{*}{ Overall score } & Dependent & 10.06 & 2.063 & \multirow{3}{*}{$9.06^{* *}$} \\
\hline & & & & \\
\hline & Non-dependent & 6.85 & 3.48 & \\
\hline
\end{tabular}

${ }^{* *} \mathrm{P}<0.001$

Table 4. Means, standard deviation, and $t$ tests on internet influences toward various life aspects in internet dependents and non-dependents

\begin{tabular}{|c|c|c|c|c|}
\hline Internet Influence on Life Aspects & $\mathrm{CP}$ & Mean & SD & T-test \\
\hline Daily activity & $\begin{array}{c}\text { Dependent } \\
\text { Non-dependent }\end{array}$ & $\begin{array}{l}6.53 \\
3.51\end{array}$ & $\begin{array}{l}1.21 \\
1.02\end{array}$ & $2.42^{*}$ \\
\hline School achievement & $\begin{array}{c}\text { Dependent } \\
\text { Non-dependent }\end{array}$ & $\begin{array}{l}4.43 \\
1.16\end{array}$ & $\begin{array}{l}1.88 \\
0.83\end{array}$ & $3.56^{*}$ \\
\hline Mental/ Physical health & $\begin{array}{c}\text { Dependent } \\
\text { Non-dependent }\end{array}$ & $\begin{array}{l}3.93 \\
0.94\end{array}$ & $\begin{array}{l}2.55 \\
1.05\end{array}$ & $2.79^{*}$ \\
\hline Family board relation & $\begin{array}{c}\text { Dependent } \\
\text { Non-dependent }\end{array}$ & $\begin{array}{l}7.44 \\
2.39\end{array}$ & $\begin{array}{l}1.92 \\
1.14\end{array}$ & $1.83^{*}$ \\
\hline School or teacher relation & $\begin{array}{c}\text { Dependent } \\
\text { Non-dependent }\end{array}$ & $\begin{array}{l}2.00 \\
1.95\end{array}$ & $\begin{array}{l}1.83 \\
1.48\end{array}$ & 2.66 \\
\hline Feeding & $\begin{array}{c}\text { Dependent } \\
\text { Non-dependent }\end{array}$ & $\begin{array}{l}3.04 \\
1.87\end{array}$ & $\begin{array}{l}1.44 \\
0.73\end{array}$ & 1.09 \\
\hline Peer relation & $\begin{array}{c}\text { Dependent } \\
\text { Non-dependent }\end{array}$ & $\begin{array}{l}5.54 \\
2.12\end{array}$ & $\begin{array}{l}1.81 \\
1.21\end{array}$ & $3.33^{*}$ \\
\hline $\begin{array}{l}\text { Disrupted sleep patterns } \\
\text { and fatigue }\end{array}$ & $\begin{array}{c}\text { Dependent } \\
\text { Non-dependent }\end{array}$ & $\begin{array}{l}6.02 \\
3.59\end{array}$ & $\begin{array}{l}0.93 \\
0.07\end{array}$ & $1.61^{*}$ \\
\hline
\end{tabular}

${ }^{*} \mathrm{P}<0.01$ 
Table 5. Means, standard deviations and $t$ tests for internet dependent and non-dependent participants in SS

\begin{tabular}{|c|c|c|c|c|}
\hline Sensation Seeking & Groups & Mean & SD & T-test \\
\hline \multirow{3}{*}{ Seeking experience } & Dependent & 6.23 & 2.31 & \multirow{3}{*}{1.22} \\
\hline & & & & \\
\hline & Non-dependent & 6.51 & 2.32 & \\
\hline \multirow[b]{2}{*}{ Seeking thrill and adventure } & Dependent & 4.63 & 2.68 & \multirow[b]{2}{*}{0.527} \\
\hline & Non-dependent & 4.86 & 2.83 & \\
\hline \multirow{3}{*}{ Disinhibition } & Dependent & 3.83 & 1.60 & \multirow{3}{*}{$3.69^{* *}$} \\
\hline & & & & \\
\hline & Non-dependent & 3.94 & 1.66 & \\
\hline \multirow{3}{*}{ Susceptibility to boredom } & Dependent & 4.64 & 1.21 & \multirow{3}{*}{2.83} \\
\hline & & & & \\
\hline & Non-dependent & 4.49 & 1.29 & \\
\hline \multirow{3}{*}{ Overall score } & Dependent & 11.09 & 3.63 & \multirow{3}{*}{4.78} \\
\hline & & & & \\
\hline & Non-dependent & 11.85 & 3.48 & \\
\hline
\end{tabular}

${ }^{* *} \mathrm{P}<0.001$

Table 6. Regression results of sensation seeking (four dimensions and overall) in CP patients with internet dependence

\begin{tabular}{|c|c|c|c|c|c|c|}
\hline Participants & Criterion & Predictor (s) & Beta & $\mathbf{T}$ & $\mathbf{R}^{2}$ & $\mathbf{F}$ \\
\hline \multirow{5}{*}{ Dependents } & Compulsive use/ Withdrawal & Susceptibility to boredom & 0.019 & $1.08^{*}$ & 0.031 & $9.71^{*}$ \\
\hline & Tolerance & Disinhibition & 0.107 & $2.51^{*}$ & 0.064 & $6.35^{*}$ \\
\hline & Related problems: Family, school, health & Disinhibition & 0.104 & $0.89^{*}$ & 0.080 & 5.95 \\
\hline & $\begin{array}{l}\text { Related problems: Interpersonal and } \\
\text { Finance }\end{array}$ & Disinhibition & 0.038 & $0.31^{*}$ & 0.090 & $8.83^{*}$ \\
\hline & Overall score & $\begin{array}{c}\text { Susceptibility to boredom } \\
\text { Disinhibition }\end{array}$ & 0.027 & $1.01^{*}$ & 0.029 & $11.19^{*}$ \\
\hline
\end{tabular}

${ }^{*} \mathrm{P}<0.01$

Table 7. For the whole participants (Internet dependents and non-dependents ( $N=150)$ the regression of SS on 4 dimensions of and overall internet dependence subscales: The standardized regression coefficients and coefficients of determination

\begin{tabular}{|c|c|c|c|c|c|c|}
\hline Participants & Criterion & Predictor (s) & Beta & $\mathbf{T}$ & $\mathbf{R}^{2}$ & $\mathbf{F}$ \\
\hline \multirow{5}{*}{$\begin{array}{l}\text { Dependents } \\
\text { and } \\
\text { non-dependent }\end{array}$} & Compulsive use/ Withdrawal & Disinhibition & 0.022 & $2.08^{*}$ & 0.031 & $22.31^{*}$ \\
\hline & Tolerance & $\begin{array}{l}\text { Susceptibility to bore- } \\
\text { dom }\end{array}$ & 0.117 & $3.51^{*}$ & 0.064 & $12.25^{*}$ \\
\hline & $\begin{array}{l}\text { Related problems: Family, school, } \\
\text { health }\end{array}$ & Disinhibition & 0.204 & $3.89^{*}$ & 0.080 & 10.95 \\
\hline & $\begin{array}{l}\text { Related problems: Interpersonal } \\
\text { and Finance }\end{array}$ & $\begin{array}{l}\text { Seeking thrill and ad- } \\
\text { venture }\end{array}$ & 0.098 & $2.31^{*}$ & 0.090 & $13.63^{*}$ \\
\hline & Overall score & Disinhibition & 0.067 & $2.01^{*}$ & 0.029 & $17.39^{*}$ \\
\hline
\end{tabular}


et al. (2000) found that 43 (12.6\%) of 342 undergraduate students from an American university were internet addicts. They showed that there is a significant relationship between addiction to the internet and sensation seeking [30]. Sensation seeking and adventure seeking scores were significantly lower in individuals who were dependent on the internet compared to the rest of the samples. Lavin et al. clarified that dependence on the internet is a mental or social phenomenon rather than a physical issue, as per Zuckerman's SSS scale [30].

Lavin et al. (1999) also studied the attitudes and behaviors of more than 300 college students towards internet and sensation seeking impulse using Zuckerman's SSS scale. They found that individuals dependent on the internet obtained lower scores in sensation seeking, adventure seeking and excitement seeking scales, which was far from expectations. Contrarily, Lin (2002) and Tosun (2010) conducted a study on high school students in Taiwan and university students from Turkey, respectively, and reported higher scores for sensation seeking and lack of inhibition scale among internet users. They did not find any significant correlation between the scores of the internet dependent samples and the rest of samples in terms of life-experiment seeking, trill, and adventure seeking $[31,32]$.

Researchers expressed that internet-dependent users (CP patients) may have a strong interest to quite their internet use, but not to the point of SS. Other possible explanations were that the SS traits of these $\mathrm{CP}$ patients may differ from the traditional sense of the concept or that SSS may be more appropriate for assessing SS through various physical activities rather than evaluation through non-physical activities. Also, due to motor limitations, CP patients find the internet easy and accessible to create relationships with other and gain different experiences. It seems that the internet serves as a linking instrument as one can surf the internet without any limitations. Finally, based on many research works, it is observed that internet technology is more entertaining, interesting, interactive, pleasant experience, and enjoyable. This can be claimed in persons with CP who are addicted to the internet [33].

This study has some research limitations. Working with CP patients was difficult because many of them lacked the ability to speak and thus, failed to appropriately answer the researcher questions. Moreover, these patients suffered from different medical conditions that made it difficult to sufficiently interact with them. There is a possibility that excessive internet usage could be a developmental and natural behavior, and therefore, interpretation of such findings must be done with caution.
It is suggested to conduct further studies with respect to the purpose of this study and age comparison among different groups. It is also suggested to design intervention plans considering the decision making process, aiming to reduce harms among internet addicts. It is also necessary to conduct psychoeducation interventions on this society in order to improve their copying styles and impulse control. Future researches in this area must explore solutions to internet dependence, by focusing on adaptive and maladaptive patterns among people with $\mathrm{CP}$ internet addiction.

\section{Conclusion}

It seems that internet applications directly or indirectly have motivated users to be online for more hours, especially in the case of individuals who are motor impaired. Based on this research result, individuals with $\mathrm{CP}$ and impaired physical activities are motivated by internal stimulus and seek their sensation from external stimulus like internet application. These people with CP surf and spent too much time in the internet as a leisure time not activity time.

\section{Acknowledgments}

We would like to thank all participants and their family. This research did not receive any specific grant from funding agencies in the public, commercial, or not for profit sectors.

\section{Conflict of Interest}

The author declared no conflicts of interest.

\section{References}

[1] American Psychiatric Association. Diagnostic and statistical manual of mental disorders (DSM-5®). Arlington: American Psychiatric Association Publishing; 2013.

[2] Young KS. Psychology of computer use: XL. addictive use of the Internet: A case that breaks the stereotype. Psychological Reports. 1996; 79(3):899-902. doi: 10.2466/pr0.1996.79.3.899

[3] Mohammadkhani P, Alkasir E, Pourshahbaz A, Massah O, Jafarian Dehkordi F, SoleimaniSefat E. Internet addiction in high school students and its relationship with the symptoms of mental disorders. Iranian Rehabilitation Journal. 2017; 15(2):141-148.

[4] Kim EJ, Namkoong K, Ku T, Kim SJ. The relationship between online game addiction and aggression, self-control and narcissistic personality traits. European Psychiatry. 2008; 23(3):212-8. doi: 10.1016/j.eurpsy.2007.10.010 
[5] Ross C, Orr ES, Sisic M, Arseneault JM, Simmering MG, Orr RR. Personality and motivations associated with facebook use. Computers in Human Behavior. 2009; 25(2):578-86. doi: 10.1016/j. chb.2008.12.024

[6] Young KS. Internet addiction: The emergence of a new clinical disorder. Cyber Psychology \& Behavior. 1998; 1(3):237-44. doi: 10.1089/cpb.1998.1.237

[7] Gross EF. Adolescent internet use: What we expect, what teens report. Journal of Applied Developmental Psychology. 2004; 25(6):633-49. doi: 10.1016/j.appdev.2004.09.005

[8] Young KS. Internet addiction: Symptoms, evaluation and treatment. Innovations in Clinical Practice. 1999; 17:19-31.

[9] Shaw M, Black DW. Internet addiction. CNS Drugs. 2008; 22(5):353-65. doi: 10.2165/00023210-200822050-00001

[10] Griffiths M. Internet abuse in the workplace: Issues and concerns for employers and employment counselors. Journal of Employment Counseling. 2003; 40(2):87-96. doi: 10.1002/j.21611920.2003.tb00859.x

[11] Griffiths M. Gambling on the internet: A brief note. Journal of Gambling Studies. 1996; 12(4):471-3. doi: 10.1007/bf01539190

[12] Tsai HF, Cheng SH, Yeh TL, Shih CC, Chen KC, Yang YC, et al. The risk factors of internet addiction: A survey of university freshmen. Psychiatry Research. 2009; 167(3):294-9. doi: 10.1016/j. psychres.2008.01.015

[13] Zhong B, Hardin M, Sun T. Less effortful thinking leads to more social networking? The associations between the use of social network sites and personality traits. Computers in Human Behavior. 2011; 27(3):1265-71. doi: 10.1016/j.chb.2011.01.008

[14] Zuckerman M. Behavioral expressions and biosocial bases of sensation seeking. Cambridge: Cambridge University Press; 1994.

[15] Zuckerman M. Sensation seeking (psychology revivals): Beyond the optimal level of arousal. Oxfordshire: Taylor \& Francis; 2014.

[16] Zuckerman M. Sensation seeking and risky behavior. Washington D.C.: American Psychological Association; 2007.

[17] Curcio AL, Mak AS, George AM. Do adolescent delinquency and problem drinking share psychosocial risk factors? A literature review. Addictive Behaviors. 2013; 38(4):2003-13. doi: 10.1016/j.addbeh.2012.12.004

[18] Yanovitzky I. Sensation seeking and alcohol use by college students: Examining multiple pathways of effects. Journal of Health Communication. 2006; 11(3):269-80. doi: $10.1080 / 10810730600613856$

[19] Buckner JE, Castille CM, Sheets TL. The five factor model of personality and employees' excessive use of technology. Computers in Human Behavior. 2012; 28(5):1947-53. doi: 10.1016/j. chb.2012.05.014

[20] Wang L, Luo J, Gao W, Kong J. The effect of internet use on adolescents' lifestyles: A national survey. Computers in Human Behavior. 2012; 28(6):2007-13. doi: 10.1016/j.chb.2012.04.007

[21] Yanovitzky I. Sensation seeking and adolescent drug use: The mediating role of association with deviant peers and prodrug discussions. Health Communication. 2005; 17(1):67-89. doi: 10.1207/s15327027hc1701_5
[22] Quilty LC, De Young CG, Oakman JM, Bagby RM. Extraversion and behavioral activation: Integrating the components of approach. Journal of Personality Assessment. 2014; 96(1):87-94. doi: 10.1080/00223891.2013.834440

[23] Massah O, Hosein Sabet F, Doostian Y, A'zami Y, Farhoudian A. The role of sensation-seeking and coping strategies in predicting addiction potential among students. Practice in Clinical Psychology. 2014; 2(3):173-80.

[24] Karami Z, Pirkhaefi A, Kowsarnia A, Massah O, Farhoodian A. Comparison of personality traits based on Temperament and Character Inventory (TCI) in opiate and stimulant abusers. Journal of Rehabilitation. 2014; 14(5):83-90.

[25] Conchar L, Bantjes J, Swartz L, Derman W. Barriers and facilitators to participation in physical activity: The experiences of a group of South African adolescents with cerebral palsy. Journal of Health Psychology. 2016; 21(2):152-63. doi: 10.1177/1359105314523305

[26] Young K. Internet addiction test [Internet]. 2008 [Updated 2008 November 30] available from: http://netaddiction.com/ internet-addiction-test/

[27] Shapira NA, Lessig MC, Goldsmith TD, Szabo ST, Lazoritz M, Gold MS, et al. Problematic internet use: Proposed classification and diagnostic criteria. Depression and Anxiety. 2003; 17(4):20716. doi: 10.1002/da.10094

[28] Bakken IJ, Wenzel HG, Götestam KG, Johansson A, ØREN A Internet addiction among Norwegian adults: A stratified probability sample study. Scandinavian Journal of Psychology. 2009; 50(2):121-7. doi: 10.1111/j.1467-9450.2008.00685.x

[29] Park SK, Kim JY, Cho CB. Prevalence of internet addiction and correlations with family factors among South Korean adolescents. Adolescence. 2008; 43(172):895-909. PMID: 19149152

[30] Lavin M, Marvin K, Mclarney A, Nola V, Scott L. Sensation seeking and collegiate vulnerability to internet dependence. CyberPsychology \& Behavior. 1999; 2(5):425-30. doi: 10.1089/ cpb.1999.2.425

[31] Lin SS, Tsai CC. Sensation seeking and internet dependence of Taiwanese high school adolescents. Computers in Human Behavior. 2002; 18(4):411-26. doi: 10.1016/s0747-5632(01)00056-5

[32] Tosun LP, Lajunen T. Does internet use reflect your personality? Relationship between Eysenck's personality dimensions and internet use. Computers in Human Behavior. 2010; 26(2):162-7. doi: $10.1016 /$ j.chb.2009.10.010

[33] Fisoun V, Floros G, Siomos K, Geroukalis D, Navridis K. Internet addiction as an important predictor in early detection of adolescent drug use experience-implications for research and practice. Journal of Addiction Medicine. 2012; 6(1):77-84. doi: 10.1097/adm.0b013e318233d637 